УДК 8

DOI $10.21661 / \mathrm{r}-467957$

\title{
M.M. Патракеев
}

\section{ЗВУКОВАЯ МЕТАФОРА В ХУДОЖЕСТВЕННОЙ ПРАКТИКЕ СИМВОЛИЗМА}

Аннотация: цуелью данной статьи является рассмотрение феномена звуковой метафоры, который наиболее полно проявляется в поэтическом тексте и наиболее осознанно используется в рамках символизма как направления в искусстве, а также выявление семиотической структуры стихотворения П. Верлена «Languеur». Для достижения поставленной цели в работе проводится лингвосемиотический анализ стихотворения, который решает следующие задачи: выявление семиотических технологий, использованных поэтом, и последующуая интерпретация стихотворения.

Ключевые слова: символизм в литературе, семиотика, поэтический текст, иконичность, звуковой символизм, звуковая метафора, символ.

\section{M.M. Patrakeev}

\section{SOUND METAPHOR IN THE ARTISTIC PRACTICE OF SYMBOLISM}

Abstract: the purpose of this article is to examine the phenomenon of sound metaphor manifested in the best way in poetic texts and the most consciously used within symbolism as an art movement; and to identify the semiotic structure of the poem «Langueur» by P. Verlaine as well. In order to achieve this purpose, a linguo-semiotic analysis is undertaken which solves the following tasks: identification of the semiotic techniques used by the poet, and the subsequent interpretation of the poem.

Keywords: symbolism in literature, semiotics, poetic text, iconism, sound symbolism, sound metaphor, symbol.

Рассмотрим явления звукового символизма и их смысловые функции на примере хорошо известного стихотворения Поля Верлена «Langueur». 
Примечание. Поль Верлен - один из ключевых представителей франиузского символизма, чья лирика во многом заложила и развила поэтику данного художественного течения. Поскольку теория символизма непосредственно связана с понятием символа как «более действенного, чем собственно образ, художественного орудия, помогающего прорваться сквозь покров повседневности к сверхвременной идеальной сущности мира, его трансиендентной Красоте» [5, с. 379], вполне оправданным представляется выбор этого автора и этого текста для анализа.

Данное стихотворение запечатлевает крах аполлонического начала перед дионисийским [4, с. 19-22], что, как будет продемонстрировано далее, выражается на всех структурных уровнях произведения.

Стихотворение представляет собой 14 строк, организованных по «французскому» принципу твердой сонетной формы с нарушением последовательности в терцетах: abba abba cdd cee [1, c. 411-412]. Строфы разделены на 2 катрена и 2 терцета, первые из которых связаны двумя идентичными охватными рифмами, а вторые - двумя смежными и одной общей перекрестной; однако, в то время как катрены построены по образцу традиционной формы, терцеты составляют зеркальную по отношению к канону рифму, т. е. вместо ожидаемой последовательности $c c d$ eed используется $c d d$ cee. Таким образом, поэт, нарушая форму, обманывает ожидания, продиктованные традицией, что свидетельствует о новаторстве стихотворения.

Система вокализма в стихотворении построена на регулярном повторе носовой фонемы [ã] и лабиализованных [œ]/[ә] и [ø], первая из которых символизирует аполлоническое начало с его аристократическим носовым звучанием, а остальные - дионисийское начало через характерную артикуляцию губ, передающую необузданность и дикость. Фонема [ã] используется в стихотворении 18 раз, из которых 16 в первых двух четверостишиях и передает совместно аристократизм и некую слабость лирического героя. Фонемы [œ]/[ə] и [ø], наоборот, создают образ грубости и силы. Суммарно фонемы использованы 21 раз, причем появляются и [ã], и [œ] впервые в названии стихотворения «langueur»- таким 
образом, очевидно противопоставление упомянутых выше лабиализованных и носовых фонем. Учитывая контрастное расположение фонем [ã] и [œ]/[ə]/[ø], также будет уместно вспомнить близкий рассматриваемому поэтический текст стихотворение «Гласные» А. Рембо, где фонемы получают синестетическое описание через цвета: «A noir E blanc» («A - чёрный, белый - E»), что создает впечатление монохромного изображения античной керамики. Однако цвета, а вслед за ними и идейное наполнение, решаются поэтом иначе (табл. 1).

Таблица 1

Количественное распределение носовых

и лабиализованных фонем в стихотворении

\begin{tabular}{|c|c|c|c|c|c|c|c|c|c|c|c|c|}
\hline \multirow{2}{*}{\multicolumn{2}{|c|}{$\begin{array}{c}\text { Дифференциальный } \\
\text { признак }\end{array}$}} & \multicolumn{4}{|c|}{ Носовые } & \multicolumn{7}{|c|}{ Лабиализованные } \\
\hline & & {$[\tilde{a}]$} & {$[\tilde{\varepsilon}]$} & {$[\tilde{œ}]$} & [ก] & [œ] & {$[\varnothing]$} & [ə] & {$[\mathrm{y}]$} & {$[\mathrm{u}]$} & [0] & [o] \\
\hline \multicolumn{2}{|c|}{ Название } & 1 & - & - & - & 1 & - & - & - & - & - & - \\
\hline \multirow{2}{*}{ Катрены } & I & 9 & 2 & 1 & 1 & 1 & - & 3 & 1 & 1 & 4 & 1 \\
\hline & II & 7 & - & 2 & 3 & 3 & 2 & 1 & - & 2 & - & 4 \\
\hline \multirow{2}{*}{ Терцеты } & I & 1 & 1 & 1 & - & - & 1 & 1 & 4 & 6 & - & 2 \\
\hline & II & 1 & - & 5 & 2 & 4 & 3 & 1 & - & 3 & 1 & 1 \\
\hline \multicolumn{2}{|l|}{ Всего } & 19 & 3 & 9 & 6 & 9 & 6 & 6 & 5 & 9 & 5 & 8 \\
\hline
\end{tabular}

Рифмовка стихотворения так же строится на основе представленного выше противопоставления носовых и лабиализованных фонем: катрены рифмуются на

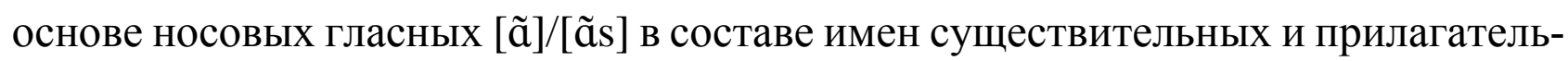
ных, а терцеты - лабиализованной [ø] в составе существительных совместно с последовательной рифмой на [iR] и [iz] глагольного характера.

С точки зрения грамматики представляется эффективным использование принципов грамматического анализа поэтического текста, представленных в статье «Поэзия грамматики и грамматика поэзии» Р.О. Якобсона [6, с. 533-535]. Так, настоящее стихотворение имеет несколько планов: первый катрен достаточно однороден по отношению к выраженным категориям: в основном здесь представлены утвердительные предложения с формами глаголов в настоящем времени действительного залога в I и III лицах. Второй катрен уже расширяет грамматический диапазон используемых форм: появляются неличные формы 
глаголов и восклицательный тип предложения; но исчезает I лицо. Первый терцет продолжает намеченную тенденцию к разнообразию грамматических форм, но именно здесь грамматические категории так или иначе изменяются, создавая тем самым контраст на фоне предыдущих строф: прослеживается употребление уже не только неличных форм глагола или же личных форм настоящего времени, но и прошедшего в вопросительном предложении, вместе с чем представлен и страдательный залог в восклицательных. Второй терцет, наоборот, уменьшает разнообразие грамматических форм вплоть до полного их исчезновения: единственное сложное восклицательное предложение выражает грамматические категории лишь в придаточных предложениях, в то время как главные представляют собой назывные предложения. Таким образом, стихотворение постепенно расширяет диапазон грамматических форм, но в то же время исключает I лицо вплоть до полного исчезновения данной категории и ограничивает использование глагольных форм (табл. 2).

Таблица 2

Выражение грамматических значений и их изменение в стихотворении

\begin{tabular}{|c|c|c|c|c|c|c|c|c|c|c|c|c|c|}
\hline \multirow[b]{2}{*}{ 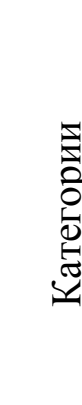 } & & \multicolumn{3}{|c|}{ Время } & \multicolumn{2}{|c|}{ Залог } & \multicolumn{3}{|c|}{ Лицо } & \multicolumn{4}{|c|}{ Тип предложения } \\
\hline & & 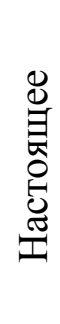 & 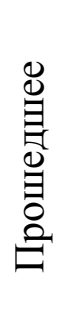 & 0 & 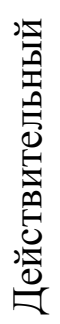 & 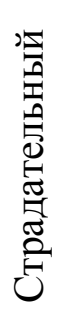 & - & $\Xi$ & 曰 & 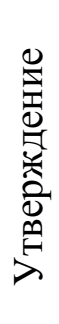 & 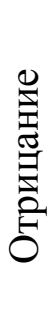 & 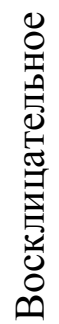 & $\begin{array}{l}8 \\
0 \\
0 \\
0 \\
0 \\
0 \\
0 \\
0 \\
0 \\
0 \\
0\end{array}$ \\
\hline \multirow{8}{*}{ 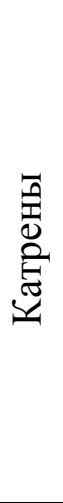 } & \multirow{4}{*}{ • } & + & - & - & + & - & + & - & - & + & - & - & - \\
\hline & & + & - & - & + & - & + & - & - & + & - & - & - \\
\hline & & + & - & - & + & - & + & - & - & + & - & - & - \\
\hline & & + & - & - & + & - & - & - & + & + & - & - & - \\
\hline & \multirow{4}{*}{ 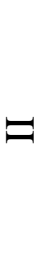 } & + & - & - & + & - & - & - & + & + & - & - & - \\
\hline & & + & - & - & + & - & - & - & + & + & - & - & - \\
\hline & & + & - & + & + & - & - & - & - & - & + & + & - \\
\hline & & - & - & + & + & - & - & - & - & - & + & + & - \\
\hline \multirow{3}{*}{ 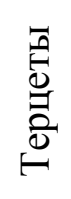 } & \multirow{3}{*}{ • } & - & - & + & + & - & - & - & - & - & + & + & - \\
\hline & & + & + & - & + & + & - & + & + & + & - & + & + \\
\hline & & + & - & + & - & + & - & - & + & + & + & + & - \\
\hline
\end{tabular}

4 https://interactive-plus.ru

Содержимое доступно по лицензии Creative Commons Attribution 4.0 license (CC-BY 4.0) 


\begin{tabular}{|c|c|c|c|c|c|c|c|c|c|c|c|c|}
\hline \multirow{3}{*}{$\Xi$} & + & - & + & + & - & - & - & + & + & - & + & - \\
\hline & + & - & + & + & - & - & + & + & + & - & + & - \\
\hline & + & - & + & + & - & - & + & + & + & + & + & - \\
\hline
\end{tabular}

Ритмика стихотворения как взаимодействие синтаксического оформления с рифмой представлена следующим образом: если катрены представляют собой четко разделенные на стихи предложения с обязательной цезурой в середине, то терцеты ломают заданный в начале ритм через обилие цезур, обусловленных синтаксическим дроблением стихов на восклицательные и вопросительные предложения в первом терцете, а также на обособленные в начале стихов «seul» во втором (табл. 3). Таким образом, во всей строгой структуре стихотворения, начиная с фонематического оформления и кончая ритмикой, мы можем наблюдать «трещину», выраженную через анормальность первого терцета.

Таблица 3

Ритмическая структура стихотворения

\begin{tabular}{|c|c|c|c|c|c|c|c|c|c|c|c|c|c|c|}
\hline \multicolumn{2}{|c|}{ Строфы } & \multicolumn{12}{|c|}{ Слоги } & \multirow{2}{*}{$\frac{\text { Всего }}{12}$} \\
\hline \multirow{8}{*}{ Катрены } & \multirow{4}{*}{ I } & $\mathrm{U}$ & $\mathrm{U}$ & $\mathrm{U}$ & - & $\mathrm{U}$ & $\mathrm{U}$ & $\mathrm{U}$ & $\mathrm{U}$ & $\mathrm{U}$ & $\mathrm{U}$ & $\mathrm{U}$ & - & \\
\hline & & $\mathrm{U}$ & $\mathrm{U}$ & $\mathrm{U}$ & $\mathrm{U}$ & - & $\mathrm{U}$ & $\mathrm{U}$ & $\mathrm{U}$ & $\mathrm{U}$ & - & & & 10 \\
\hline & & $\mathrm{U}$ & $\mathrm{U}$ & $\mathrm{U}$ & - & $\mathrm{U}$ & $\mathrm{U}$ & $\mathrm{U}$ & $\mathrm{U}$ & $\mathrm{U}$ & $\mathrm{U}$ & - & & 11 \\
\hline & & $\mathrm{U}$ & $\mathrm{U}$ & - & $\mathrm{U}$ & $\mathrm{U}$ & $\mathrm{U}$ & $\mathrm{U}$ & $\mathrm{U}$ & $\mathrm{U}$ & $\mathrm{U}$ & - & & 11 \\
\hline & \multirow{4}{*}{ II } & $\mathrm{U}$ & $\mathrm{U}$ & $\mathrm{U}$ & $\mathrm{U}$ & $\mathrm{U}$ & $\mathrm{U}$ & - & $\mathrm{U}$ & $\mathrm{U}$ & $\mathrm{U}$ & - & & 11 \\
\hline & & $\mathrm{U}$ & $\mathrm{U}$ & $\mathrm{U}$ & - & $\mathrm{U}$ & $\mathrm{U}$ & $\mathrm{U}$ & $\mathrm{U}$ & $\mathrm{U}$ & $\mathrm{U}$ & $\mathrm{U}$ & - & 12 \\
\hline & & $\mathrm{U}$ & $\mathrm{U}$ & $\mathrm{U}$ & - & $\mathrm{U}$ & $\mathrm{U}$ & $\mathrm{U}$ & $\mathrm{U}$ & $\mathrm{U}$ & $\mathrm{U}$ & $\mathrm{U}$ & - & 12 \\
\hline & & $\mathrm{U}$ & $\mathrm{U}$ & $\mathrm{U}$ & - & $\mathrm{U}$ & $\mathrm{U}$ & $\mathrm{U}$ & $\mathrm{U}$ & $\mathrm{U}$ & $\mathrm{U}$ & $\mathrm{U}$ & - & 12 \\
\hline \multirow{6}{*}{ Терцеты } & \multirow{3}{*}{ I } & $\mathrm{U}$ & $\mathrm{U}$ & $\mathrm{U}$ & - & $\mathrm{U}$ & $\mathrm{U}$ & $\mathrm{U}$ & $\mathrm{U}$ & $\mathrm{U}$ & $\mathrm{U}$ & $\mathrm{U}$ & - & 12 \\
\hline & & - & $\mathrm{U}$ & $\mathrm{U}$ & - & $\mathrm{U}$ & - & $\mathrm{U}$ & $\mathrm{U}$ & $\mathrm{U}$ & $\mathrm{U}$ & $\mathrm{U}$ & - & 12 \\
\hline & & - & $\mathrm{U}$ & $\mathrm{U}$ & - & $\mathrm{U}$ & $\mathrm{U}$ & $\mathrm{U}$ & - & $\mathrm{U}$ & $\mathrm{U}$ & $\mathrm{U}$ & - & 12 \\
\hline & \multirow{3}{*}{ II } & - & $\mathrm{U}$ & $\mathrm{U}$ & $\mathrm{U}$ & $\mathrm{U}$ & $\mathrm{U}$ & - & $\mathrm{U}$ & $\mathrm{U}$ & $\mathrm{U}$ & - & & 11 \\
\hline & & - & $\mathrm{U}$ & $\mathrm{U}$ & $\mathrm{U}$ & $\mathrm{U}$ & $\mathrm{U}$ & $\mathrm{U}$ & - & $\mathrm{U}$ & $\overline{\mathrm{U}}$ & $\mathrm{U}$ & - & 12 \\
\hline & & - & $\mathrm{U}$ & $\mathrm{U}$ & $\mathrm{U}$ & $\mathrm{U}$ & $\mathrm{U}$ & $\mathrm{U}$ & - & $\mathrm{U}$ & $\mathrm{U}$ & $\mathrm{U}$ & - & 12 \\
\hline
\end{tabular}

При рассмотрении семантики данного стихотворения так же выявляются закономерности. Так, поэт, ассоциируя себя с Римской империей в период упадка, перенимает на себя ее гибель, что находит свое выражение в своеобразном использовании местоимений: личное местоимения «је» в первом катрене 
переходит в оппозицию неопределенных местоимений «tout» и «rien», которая разрешается в неопределенно-личное местоимение «оn».

Представленное выше изобилие смысловых уровней стихотворения можно представить с помощью актантной модели. Согласно актантной модели А.Ж. Греймаса [2, с. 163], в данном стихотворении субъект высказывания представлен поэтом, который обращается к миру. Само же действие представлено конфликтом между патрициями и варварами (или рабами), которые представляют собой аполлоническое и дионисийское начала (табл. 4).

Таблица 4

Реализация актантов в стихотворении по модели А.Ж. Греймаса

\begin{tabular}{|l|l|}
\hline \multicolumn{1}{|c|}{ Актант } & \multicolumn{1}{|c|}{ Реализация актантов в стихотворении } \\
\hline Субъект & Поэт \\
\hline Объект & Мир \\
\hline Адресант & Аполлоническое начало \\
\hline Адресат & Дионисийское начало \\
\hline Помощник & Патриции \\
\hline Противник & Варвары/рабы \\
\hline
\end{tabular}

Сюжет лирического произведения реализуется в форме мифа, то есть вымысла, соотнесенного с реальностью [3, с. 107]. Так, П. Верлен проецирует на себя упадок Римской империи. В разрушении, бедности и упадке, окружающих его, поэт видит не простое завоевание Рима варварами, а уничтожение аполлонического начала дионисийским. Поэт предчувствует в величии и красоте Римской империи ее же гибель.

Таким образом, с помощью семиотического анализа мы можем проследить, как поэт усложняет и, в конечном счете, стягивает образы в единый символ, что обеспечивается на всех уровнях языка путем взаимообусловленности плана выражения и плана содержания во всех аспектах знаковых отношений.

\section{Сиисок литературы}

1. Гаспаров М.Л. Сонет // Литературный энциклопедический словарь. - М.: Сов. энциклопедия, 1987. - С. 411-412. 
2. Греймас А.-Ж. Размышления об актантных моделях // Французская семиотика: от структурализма к постструктурализму / Пер. с фр. - М.: Прогресс, 2000. - C. $153-170$.

3. Лотман Ю.М. Анализ поэтического текста: структура стиха // О поэтах и поэзии. - СПб.: Искусство-СПБ, 1996. - С. 18-253.

4. Ницше Ф. Рождение трагедии их духа музыки // Малое собрание сочинений. - СПб.: Азбука-классика, 2010. - С. 5-134.

5. Роднянская И.Б. Символизм / И.Б. Роднянская, Л.К. Долгополов // Литературный энциклопедический словарь. - М.: Сов. энциклопедия, 1987. - С. 379380.

6. Якобсон Р.О. Поэзия грамматики и грамматика поэзии // Семиотика: Антология / Сост. Ю.С. Степанова. - 2-е изд., испр. и доп. - М.: Академический проект; Екатеринбург: Деловая книга, 2001. - С. 525-548.

\section{References}

1. Gasparov, M.L. (1987). Sonet. Literaturnyi entsiklopedicheskii slovar', pp. 411-412. M.: Sov. Entsiklopediia.

2. (2000). Greimas A.-Zh. Razmyshleniia ob aktantnykh modeliakh. Frantsuzskaia semiotika: ot strukturalizma k poststrukturalizmu, pp. 153-170. M.: Progress.

3. Lotman, Iu. M. (1996). Analiz poeticheskogo teksta: struktura stikha. O poetakh i poezii, pp. 18-253. SPb.: Iskusstvo-SPB.

4. Nitsshe, F. (2010). Rozhdenie tragedii ikh dukha muzyki. Maloe sobranie sochinenii, pp. 5-134. SPb.: Azbuka-klassika.

5. Rodnianskaia, I.B., \& Dolgopolov, L.K. (1987). Simvolizm. Literaturnyi entsiklopedicheskii slovar', pp. 379-380. M.: Sov. Entsiklopediia.

6. Iakobson, R.O. (2001). Poeziia grammatiki i grammatika poezii. Semiotika: Antologiia, pp. 55-548. M.: Akademicheskii proekt; Ekaterinburg: Delovaia kniga.

Патракеев Михаил Михайлович - магистрант НОУ ВО «Санкт-Петербургский гуманитарный университет профсоюзов», Россия, Санкт-Петербург. 
Patrakeev Mikhail Mikhailovich - graduate student at Saint Petersburg University of Humanities and Social Sciences, Russia, Saint-Petersburg. 